2. Galactose-6-phosphate is not an intermediate in this reaction.

3. The formation of an acid-stable ester from galactose has been observed occasionally with extracts of galactose-adapted yeast.

4. There is no evidence for the accumulation of galactose-1-phosphate during the pre-adaptive period.
I wish to thank Dr D. J. Bell for a gift of D-tagatose originally obtained from Prof. T. Reichstein, Dr F. R. Whatley for a gift of barium glucose-6-phosphate, and Dr M. Stephenson, F.R.S., Dr E. F. Gale, and Dr R. Davies for their helpful criticism and encouragement. My thanks are also due to the Medical Research Council for a training grant and to Gonville and Caius College for a studentship.

\title{
REFERENCES
}

Berenblum, I. \& Chain, E. (1938). Biochem. J. 32, 295.

Berger, L., Slein, M., Colowick, S. P. \& Cori, C. F. (1945-6). J. gen. Physiol. 29, 379.

Colowick, S. P. \& Kalckar, H. M. (1943). J. biol. Chem. 148, 117.

Cori, G. T. \& Cori, C. F. (1932). J. biol. Chem. 94, 561.

Fiske, C. H. \& Subbarow, Y. (1925). J. biol. Chem. 66, 375.

Grant, G.. A. (1935). Biochem. J. 29, 1661.

Hanes, C. S. (1940). Proc. Roy. Soc. B, 129, 174.

Harding, V. J. \& Grant, G. A. (1931-2). J. biol. Chem. 94, 529.

Hvistendahl, B. (1932). Svensk kem. Tidskr. 44, 156.

Kosterlitz, H. W. (1939). Biochem. J. 33, 1087.

Kosterlitz, H. W. (1943a). Biochem. J. 37, 318.

Kosterlitz, H. W. (1943b). Biochem. J. 37, 322.

Krebs, H. A. (1933). Hoppe-Seyl. Z. 217, 191.

Levene, P. A. \& Raymond, A. L. (1931). J. biol. Chem. 92, 765.
Meijbaum, W. (1939). Hoppe-Seyl. Z. 258, 117.

Mickle, H. (1948). J. R. micr. Soc. 68, 10.

Needham, D. M. (1942). Biochem. J. 36, 113.

Reiner, J. M. (1947). J. gen. Physiol. 30, 355.

Reithel, F. J. (1945). J. Amer. chem. Soc. 67, 1056.

Robison, R. \& Morgan, W. T. J. (1930). Biochem. J. 24, 119.

Roe, J. H. (1934). J. biol. Chem. $107,15$.

Somogyi, M. (1945). J. biol. Chem. 160, 61.

Spiegelman, S. (1945). Ann. Mo. bot. Gdn, 32, 139.

Spiegelman, S. (1947). Cold Spr. Harb. Sym. quant. Biol.11, 256.

Spiegelman, S., Reiner, J. M. \& Morgan, J. (1947). Arch. Biochem. 13, 113.

Stephenson, M. \& Yudkin, J. (1936). Biochem. J. 30, 506.

Umbreit, W. W., Burris, R. H. \& Stauffer, J. F. (1945). Manometric Techniques and Related Methods for the Study of Tissue Metabolism. Minneapolis: Burgess Publishing Company.

\section{Studies on the Lens}

\author{
By M. LANGHAM AND H. DAVSON, Department of Physiology, University College, London
}

(Received 1 October 1948)

\section{POST-MORTEM CHANGES IN THE MINERAL CONTENT}

Our knowledge of the composition and metabolism of the lens has been gained almost exclusively from work on the excised organ, and it is therefore of first importance that post-mortem changes should be fully understood. It might be thought that the use of normal aqueous humour as a bathing medium for the excised lens would make such a study supererogatory, but the results described below show that, even when the lens is left undisturbed in the dead eye, important changes in its mineral content (characteristic of those taking place in a dying tissue) occur within a few hours.

\section{EXPERIMENTAL}

To minimize variance due to age, adult rabbits were used in all the experiments described with this species. Except where otherwise stated, the sheep eyes were received from the slaughterhouse within approximately $2 \mathrm{hr}$. of death.
After removing the aqueous humour and cutting away the posterior half of the eye the lens was removed by placing the anterior half of the eye on a flat dish, cornea downwards, reflecting back the curved scleral wall and cutting the suspensory ligament. Before being weighed, the lens was blotted on filter paper. For analysis, the proteins were precipitated by the Somogyi (1930) method and the filtrate made up to a definite volume. Chloride was estimated by the $\mathrm{AgIO}_{3}$ method of Sendroy (1937). When radioactive isotopes were used, activity was measured in the filtrate on a standard Geiger counter apparatus with the counter described by Maurice (1948). Radioactive sodium $\left({ }^{24} \mathrm{Na}\right)$ in the form of $\mathrm{NaCl}$, and bromine $\left({ }^{82} \mathrm{Br}\right)$ in the form of $\mathrm{NH}_{4} \mathrm{Br}$ were injected intravenously in isotonic solutions, without anaesthesia. After the experimental period the animal was killed by a blow on the neck, and the eyes, together with blood samples, were taken immediately.

For the in vitro study of the 'diffusion out' of chloride from the lens, the latter was placed in isotonic $\mathrm{Na}_{2} \mathrm{SO}_{4}$ solution, while for the 'diffusion in' of sucrose, aqueous humour was diluted with $0 \cdot 3$ vol. of an isotonic sucrose solution. Sucrose was determined by hydrolyzing the Somogyi filtrate of the macerated lens with dilute $\mathrm{H}_{2} \mathrm{SO}_{4}$, and estimating the reducing value by the Hagedorn-Jensen method. 


\section{RESULTS}

As a criterion for the normal condition of the lens the chloride content was first chosen. Preliminary experiments revealed that the chloride contents of the lenses of a pair of eyes removed immediately after death did not differ significantly; thus, the mean of the chloride contents of ten left sheep eyes was $43 \cdot 8 \pm 0 \cdot 2$ whilst that for the right eyes was $43 \cdot 7 \pm 0 \cdot 2$. In the first study, therefore, the two eyes were excised from the freshly killed animal; the lens of one was submitted to analysis immediately, whilst that of the other was analyzed after it had remained in the excised eye for a period of some hours. In Table 1 the chloride contents of the pairs of eyes are

Table 1. Post-mortem changes in the chloride content of lenses allowed to remain in the excised eye

\begin{tabular}{|c|c|c|c|c|}
\hline \multirow[b]{2}{*}{ Species } & \multirow{2}{*}{$\begin{array}{c}\text { Time test } \\
\text { lens left } \\
\text { in eye } \\
(\mathrm{hr} .)\end{array}$} & \multirow{2}{*}{$\underset{\left({ }^{\circ}\right)}{\text { Temp. }}$} & \multicolumn{2}{|c|}{$\begin{array}{l}\text { Chloride content } \\
\text { (mg./100 g.) }\end{array}$} \\
\hline & & & Control lens & Test lens \\
\hline Rabbit & $\begin{array}{l}2 \\
2 \\
4 \\
4 \\
5 \\
4 \cdot 5 \\
6 \cdot 5 \\
7 \cdot 0 \\
5 \cdot 25\end{array}$ & $\begin{array}{r}0 \\
0 \\
0 \\
0 \\
0 \\
0 \\
0 \\
0 \\
20\end{array}$ & $\begin{array}{l}31 \cdot 9 \\
32 \cdot 1 \\
30 \cdot 7 \\
29 \cdot 9 \\
33 \cdot 3 \\
31 \cdot 0 \\
25 \cdot 6 \\
36 \cdot 4 \\
33 \cdot 6\end{array}$ & $\begin{array}{l}\mathbf{3 1} \cdot 0 \\
\mathbf{3 3} \cdot \mathbf{7} \\
\mathbf{3 7 \cdot 3} \\
\mathbf{3 5} \cdot \mathbf{1} \\
\mathbf{3 7 \cdot 1} \\
\mathbf{3 3 \cdot 9} \\
\mathbf{3 1} \cdot 0 \\
\mathbf{3 9} \cdot \mathbf{3} \\
\mathbf{4 6} \cdot \mathbf{3}\end{array}$ \\
\hline & & Mean & $34.0 \pm 0.79$ & $39 \cdot 5 \pm 1 \cdot 14$ \\
\hline Sheep & $\begin{array}{l}6 \cdot 0 \\
6 \cdot 0 \\
3 \cdot 0 \\
3 \cdot 0\end{array}$ & $\begin{array}{l}20 \\
20 \\
20 \\
20\end{array}$ & $\begin{array}{l}39 \cdot 4 \\
33 \cdot 1 \\
35 \cdot 6 \\
38 \cdot 2\end{array}$ & $\begin{array}{l}45 \cdot 9 \\
43 \cdot 9 \\
37 \cdot 6 \\
43 \cdot 0\end{array}$ \\
\hline & & Mean & $36 \cdot 6 \pm 0 \cdot 64$ & $42 \cdot 6 \pm 1 \cdot 0$ \\
\hline
\end{tabular}

shown. The results indicate that the lens left in the eye takes up chloride; thus, for rabbits, the mean chloride content of the control eyes was $34.0 \mathrm{mg}$. $/ 100 \mathrm{~g}$. whilst that of the eyes left for more than $2 \mathrm{hr}$. was $39.5 \mathrm{mg}$. $/ 100 \mathrm{~g}$.; it will be noted that the lenses left for only $2 \mathrm{hr}$. at $0^{\circ}$ showed no increase in chloride content. There is thus a post-mortem increase in the chloride content of the lens even when it is allowed to remain in the eye. It is generally assumed that the chloride content of a normal tissue is a measure of the extracellular space, the cells being virtually free from this ion; the increase in chloride content observed may, therefore, be interpreted as the result either of an increase in extrecellular space or of degenerative changes in the lens fibres which permit them to accumulate chloride. Changes in the chloride content should be paralleled by changes in the sodium content on the basis of either of these explanations. Consequently, the uptake of radioactive sodium by the lens in vivo should be less than the uptake of another, excised, lens from an artificial medium. Similarly, by use of the radioactive bromide ion, differing uptakes should be obtained under the two conditions. In Table 2 the results of diffusion experiments are shown; they indicate that when diffusion takes place from an artificial medium

Table 2. Ratio of the concentrations of isotopes in lens and in aqueous humour in vitro and in vivo studies

(For in vitro studies the lens was suspended in aqueous humour containing the isotope. For in vivo studies the isotope was injected intravenously into the animal without anaesthesia. The results are calculated from counts/100 g. of material and are expressed as mean \pm S.E. The number of experiments is given in brackets.)

$\begin{array}{ccc}\text { Tiffusion } & \begin{array}{c}\text { Mean ratio: isotope in } \\ \text { time } \\ (\mathrm{hr} .)\end{array} & \begin{array}{c}\text { lens/isotope in aqueous } \\ \text { humour }\end{array} \\ \text { Type of exp. } & 24 & 0 \cdot 29 \pm 0.01(6) \\ \text { In vitro; }{ }^{24} \mathrm{Na} & 48 & 0.36 \pm 0.07(6) \\ & 24 & 0 \cdot 29 \pm 0.03(6) \\ \text { In vitro; }{ }^{82} \mathrm{Br} & 40 & 0 \cdot 29 \pm 0.03(6) \\ & 2 & 0.03 \pm 0.02(6) \\ \text { In vivo; }{ }^{24} \mathrm{Na} & 24 & 0.06 \pm 0.01(4) \\ & 41-46 & 0.05 \pm 0.02(6) \\ \text { In vivo; }{ }^{82} \mathrm{Br} & 24-48 & 0.07 \pm 0.02(4)\end{array}$

over a period of $24-48 \mathrm{hr}$. at $0^{\circ}$ the ratio $\mathrm{Na}$ in lens $/ \mathrm{Na}$ in aqueous humour is $0 \cdot 29-0 \cdot 36$, whereas in vivo experiments gave very much smaller ratios in the region of 0.07 when the diffusion time was either 24 or $48 \mathrm{hr}$. Similarly, results with the radioactive bromide ion gave large in vitro ratios in the region of 0.29 and in vivo values of approximately 0.065 .

\section{DISCUSSION}

The primary importance of the experimental findings described here must be in emphasizing the limitation of in vitro experiments on the lens under the given conditions. In some of the experiments described the lens was merely left in the excised eye, i.e. it was surrounded by intraocular fluid during the whole time, and yet quite unmistakable changes in its chloride content took place in a few hours. In the living eye there is strong reason to believe that the aqueous humour flows continuously, being drained away at the angle of the anterior chamber to be replaced by new fluid presumably from the ciliary body; the cessation of this renewal is apparently sufficient, even with a tissue of such low metabolic activity as the lens, to cause changes in the salt content of the lens that are generally interpreted as degenerative, i.e. a breakdown of the normal permeability of the fibre cells to sodium. It is interesting that in a recent publication Palm (1948), working on the penetration of radioactive phosphorus into the lens, came to the conclusion that experiments not completed within $2 \mathrm{hr}$. of the death of the animal were altogether unreproducible. 
Although much experimental work has been done on the lens and isolated capsule there seem to be few detailed investigations of the speed of postmortem changes. On the other hand, the literature is well stocked with references to the changes in composition that occur with development of cataract, changes indicating breakdown of the normal ion permeability of the lens fibres to the sodium chloride in their environment. It is not yet possible to correlate this increase in permeability with specific metabolic changes, but consideration of the following is of interest. Experimental work of the authors (unpublished) supports the results in the literature (Bellows, 1944) indicating that there is no significant decrease of carbohydrate in the lens or aqueous humour during the first few hours following death. The deduction that the presence of glucose does not delay the degenerative changes is supported by the inability of a Krebs-Ringer phosphate medium containing glucose, or an aqueous medium to which isotonic glucose solution has been added, to retard the speed of these changes (unpublished obser. vations).

Much experimental evidence has led to general agreement that the energy required by the normal lens is obtained primarily from carbohydrate metabolism (Bellows, 1944; Fischer, 1930), and further that, unlike other active tissues, the lens has no carbohydrate reserve in the form of glycogen (Weekers \& Sullman, 1938).

If we accept these conclusions it is apparent that, following death, a factor is introduced which leads to interference in the utilization of sugar. The importance of an active endergonic metabolism in the normal tissue is further supported by the slowing of the rate of post-mortem changes following a decrease in the temperature of the lens.

\section{ESTIMATION OF EXTRACELLULAR SPACE OF LENS}

The extracellular volume of muscle has been calculated from its sodium and chloride contents on the well-supported assumption that thesse ions exist mainly or totally outside the cell; additional methods have involved the study of the uptake of a large water-soluble molecule like that of sucrose which is presumed not to penetrate the cell membrane.

The chloride contents of the rabbit and sheep lens were found by analysis to be $34 \cdot 7 \pm 0 \cdot 6 \mathrm{mg} \cdot / 100 \mathrm{~g}$. (10) and $43 \cdot 7 \pm 0 \cdot 6 \mathrm{mg} . / 100 \mathrm{~g}$. (20) (numbers in brackets refer to numbers of experiments). The aqueous humour concentrations of the same eyes, expressed as $\mathrm{mg} . / 100 \mathrm{ml}$., were 397 for the rabbit (6) and 460 for the sheep (14). Consequently the chloride space, i.e. the fraction of the weight occupied by interstitial fluid, assuming that all the chloride is present in the latter, is $\mathbf{9 . 5} \%$ for the sheep and $8.7 \%$ for the rabbit. In view of the unique growth characteristics of the lens, however, it is doubtful whether this fraction does indeed represent the true extracellular space; thus, the lens continues cell proliferation throughout life, the newly formed surface cells displacing the older ones inwards towards the centre, a process that results in the formation of a hard nucleus of old, densely packed fibres and a softer cortex of more recently formed elements. As a result of this development it is quite possible that the fibres of the densely packed nucleus, representing very old cells, contain appreciable amounts of sodium and chloride. If this is true the estimate of the extracellular space from the chloride content must give too high a value. Moreover, the cells containing sodium and chloride will be predominantly in the dense highly viscous nucleus, and will be therefore unable to attain diffusion equilibrium with their environment within an experimentally measurable period. In the present work the fraction of the lens that comes into apparent diffusion equilibrium, in respect to chloride, ${ }^{24} \mathrm{Na}$, ${ }^{82} \mathrm{Br}$ and sucrose with its environment within 24-48 hr., has been determined. We may call this the 'readily available space'. In so far as the chloride ion was concerned, the space was estimated on the basis of the amount that diffused out of the lens into an isotonic sulphate solution within 24-48 hr. For ${ }^{24} \mathrm{Na}$ the results already described on the diffusion into the lens in vivo were used for the computation. Sucrose was allowed to diffuse into the excised lens from an aqueous humour medium; in view of the post-mortem changes already described we may expect this substance to provide altogether too high a value for the 'readily available space'. This was indeed found to be the case; washing the lens, after the diffusion in sucrose, for $0.5 \mathrm{hr}$. in a sulphate medium reduced the 'sucrose space' to a value comparable with the 'readily available chloride space'.

\section{RESULTS}

The results of this investigation are summarized in Table 3. It will be seen that the 'readily available chloride space', determined by the fraction of chloride that diffuses out of the lens in 24-48 hr., is $5.5 \%$ as opposed to the value of $8 \cdot 5-9 \cdot 6 \%$ for the total chloride space. On the basis of in vivo diffusion of radioactive isotopes into the lens the 'readily available space' is $6 \cdot \mathbf{1}-6 \cdot 7 \%$. Sucrose diffuses into an available space of $13 \cdot 5 \%$, indicating the occurrence of post-mortem changes. If the lenses, after the diffusion of sucrose into them, are placed in a sucrosefree medium, there is an initial rapid diffusion of sucrose out; this rapid loss is succe日ded by a much slower loss during the next $24 \mathrm{hr}$. If the sucrose space is computed on the basis of the sucrose content after this rapid loss it averages $5.5 \%$. 
Table 3. Values of the extracellular volume of lens

\begin{tabular}{|c|c|c|}
\hline Method & $\begin{array}{l}\text { Total space } \\
(\%)\end{array}$ & $\begin{array}{c}\text { Readily } \\
\text { available } \\
\text { space (\%) }\end{array}$ \\
\hline $\begin{array}{l}\text { Chloride analysis and diffusion } \\
\text { out into } \mathrm{Na}_{2} \mathrm{SO}_{4}\end{array}$ & $\begin{array}{l}9 \cdot 6 \text { (sheep) } \\
8 \cdot 5 \text { (rabbits) }\end{array}$ & $5 \cdot 5$ (sheep) \\
\hline Diffusion of ${ }^{24} \mathrm{Na}$ in vivo & - & $6 \cdot 1$ (rabbits) \\
\hline Sucrose (diffusion into lens) & 13.5 (sheep) & 一 \\
\hline $\begin{array}{l}\text { Sucrose (diffusion into lens } \\
\text { and subsequent washing in } \\
\text { isotonic } \mathrm{Na}_{2} \mathrm{SO}_{4} \text { ) }\end{array}$ & - & $5 \cdot 46$ (sheep) \\
\hline Diffusion of ${ }^{82} \mathrm{Br}$ in vivo & - & $6 \cdot 7$ (rabbits) \\
\hline
\end{tabular}

\section{DISCUSSION}

For kinetic studies on the penetration of substances from aqueous humour into the lens fibres a knowledge of the magnitude of the effective extracellular space - the 'readily available space' discussed hereis a first essential. The results described in this paper indicate that this space is of the order of 6-7\% where in vivo studies are concerned. Owing to its greater density, the nucleus of the adult lens contains a higher concentration of potassium (expressed in mg./unit wt. of lens) than the cortex; the ratio $[\mathrm{K}] /[\mathrm{Na}]$ in the nucleus is, however, lower than that in the cortex (Bellows, 1944). If it is assumed that sodium is predominantly an extracellular ion, it might be deduced that the nucleus has a greater extracellular matrix. This conclusion appears doubtful on histological grounds since the hard, viscous, nucleus is composed of densely packed fibres. A more probable explanation for the lower ratio is that the nuclear fibres are partly permeable to sodium, thereby permitting sodium and chloride to displace potassium, an explanation with which the present findings are in agreement. It is apparent that the nucleus must have a very low metabolism indeed and this fact, coupled with the disappearance of the cell nuclei from these central cells, would support the view of an increased permeability to sodium.

\section{SUMMARY}

1. The limitation of the in vitro experiment on the excised lens is deduced from studies of the rate at which post-mortem changes occur.

2. Three methods for the determination of the 'readily available space' are described.

3. Analysis of the results shows that this space is $5 \cdot 0-5.5 \%$ of the volume of an adult sheep's lens and approximately $6 \%$ of the volume of an adult rabbit's lens.

4. From an analysis of the $\mathrm{K} / \mathrm{Na}$ ratio in the nucleus and the cortex, together with anatomical and histological evidence, it is suggested that the chloride that fails to diffuse out of the lens within 24-48 $\mathrm{hr}$. is contained in the nucleus.

We are grateful to the Medical Research Council for a grant to one of us (M.L.) and for defraying the whole cost of this work.

\title{
REFERENCES
}

Bellows, J. G. (1944). Cataract and Anomalies of the Lens. lst ed. London: Kimpton.

Fischer, F. P. (1930). Ber. dtsch. ophthal. Ges. 48, 95.

Maurice, D. (1948). J. Physiol. 107, 26 P.

Palm, E. (1948). Acta Ophthal., Kbh. Suppl. no. 32.
Sendroy, J. (1937). J. biol. Chem. 120, 335.

Somogyi, M. (1930). J. biol. Chem. 86, 655.

Weekers, R. \& Sullman, H. (1938). Arch. int. Méd. exp. 13, 483.

\section{Breakdown of Cozymase by a System from Nervous Tissue}

\author{
By H. McILWAIN AND R. RODNIGHT, Research Laboratory, Maudsley Hospital, London, S.E. 5
}

(Received 5 October 1948)

Cozymase has been observed to be unstable in many biological systems (Harden \& Young, 1906a, $b$; Schlenk, 1945; McIlwain, 1947 ; McIlwain \& Hughes, 1948). In brain tissue Mann \& Quastel (1941) and Handler \& Klein (1942) showed the loss of cozymase to be due to a system which liberated nicotinamide from the coenzyme, and which was inhibited by added nicotinamide. Since then many investigators have taken precautions to prevent the breakdown when using systems dependent on cozymase, but the breakdown has not been studied sufficiently for an assessment to be made of its significance in the normal activities of nervous tissue. Because of the important part played by cozymase itself, we considered it especially necessary to determine the speed of the breakdown, and its variation with cozymase and nicotinamide concentrations and with other factors likely to affect it in the living organism. The breakdown has been found to be very rapid, and to involve the formation of acid (see equation I, p. 474). 